\title{
"CRIATURA MIGRATORIA" (NRFH, 1, 1947, núm. 1)
}

En una carta de diciembre, 1939 - la correspondencia había empezado hacía más de un decenio-, Amado Alonso escribe a Alfonso Reyes, "la RFH me absorbe todas mis energías"1; en otra, enero de 1940, comenta, "todo el Instituto de Filología ha leído y releído emocionadamente su presentación de la $\mathrm{RFH}$, yo más que nadie, porque, naturalmente, mi resonador emocional coincidía más que ningún otro con el diapasón de ud. Gracias, gracias. En su nueva vida ${ }^{2}$, ¿no tendrá ocasión usted de escribir para nuestra revista de manera grande o chica? ¿No entrevé usted la posibilidad de poder dedicarle algún tiempo, aunque sólo se comprometa usted a reseñas y notas breves, para que le podamos incluir entre los redactores? Por último, la revista necesita suscriptores para vivir, ¿podría ud. indicar quién podría encargarse ahí con seriedad de recoger suscripciones? Me dicen aquí que Porrúa es comerciante normal para mandarnos sus cuentas, pero no nos compra (no sé bien) ¿La Casa de España?" A vuelta de correo, A. Reyes le indica que "el hombre para distribuir y colocar en México la RFH es el licenciado Da-

${ }^{1}$ Lo que sigue procede de un centenar y medio de cartas no todas, sin duda, que desde 1927 hasta 1952 intercambiaron A. Reyes y A. Alonso -transcritas por Alberto Enríquez Perea, que se preparan para publicación-; la mayoría proviene de los archivos personales, otras del archivo de El Colegio, otras de uno pequeño, pero con buenas sorpresas, que pertenece a la NRFH.

${ }^{2}$ Alfonso Reyes había sido nombrado presidente de La Casa de España, dato para el que es innecesario documento oficial, porque escribe sus cartas en papel con ese membrete. 
niel Cosío Villegas, Fondo de Cultura Económica... Él está de acuerdo. El Fondo y la Casa de España trabajan como instituciones gemelas. Él corre con editorial y librería, dirige el Fondo y es Secretario de La Casa".

Sin añadir matices, esto es, en resumen apretado, lo que significa ocuparse de una revista académica, preocuparse por su destino. Alonso pregunta por suscriptores, intercambios, autores, reseñistas. Así mantuvo la Revista de Filología Hispánica por casi siete años. En ellos y en las cartas abundan solicitudes de libros, comentarios sobre lecturas, noticias sobre obras personales, preguntas, aclaraciones, proyectos ${ }^{3}$, todo matizado con mucho entusiasmo y no poco humor.

Alfonso Reyes se preocupaba entonces por la "ciencia de la literatura" (la estilística). "Ya me cansé - escribe a Alonso en agosto de 1940- de las cosas meramente impresionistas que hice durante mi adolescencia. Ahora, al comenzar mi juventud, tengo otros anhelos. Y cuando llegue a la madurez, en los ochenta, publicaré una representación del universo a través del fenómeno poético, demostrando que Dios es poeta, aunque ripioso" 4 .

${ }^{3}$ El 31 de julio de 1940, Alonso escribe a Reyes, "Voy a preparar un libro de estudios clásicos para dárselo a usted. Todavía no he pensado el título. Lo tengo hecho en más de la mitad: Lope, Quevedo, San Juan de la Cruz, fray Luis de León, y una caracterización interna de clásicos, románticos, simbolistas y superrealismos". Además preparaba desde hacía un año cierta colección "Vida y obra de..." ("tomitos de 150 páginas"), "para difundir la obra de grandes, españoles y americanos" -Cervantes, Lugones, Nebrija, sor Juana, Unamuno... y otra colección sobre "diez o doce libros fundamentales de la lingüística".

${ }^{4}$ A. Reyes espera, el 14 de noviembre de 1940, cuartillas sobre la estilística que le enviará Alonso, las que resultan ser un artículo de regular extensión, del que prefiero extraer este párrafo: "Lo primero que se requiere, pues, es una competencia técnica en el análisis afectivo, activo, imaginativo y valorativo del lenguaje. ¿Qué hace y qué se propone la estilística con esta preparación? Atiende preferentemente a los valores poéticos, de gestación y formales (o constructivos, o estructurales, o constitutivos; la forma como un hacer de espíritu creador), en vez de los valores históricos, filosóficos, ideológicos o sociales atendidos por la crítica tradicional. Hay en el Quijote pensamientos, ideas, una profunda compresión de la vida. Esos pensamientos bien podían haberse expuesto en forma de un tratado filosófico, pero entonces no constituirían una creación poética. Hay también en el Quijote una pintura social que podría haberse expuesto informativamente; pero entonces lo social no integraría una de las grandes creaciones poéticas. La estilística tiende preferentemente a lo que de creación poética tiene la obra estudiada, o a lo que de creador tiene un poeta... La obra de arte puede y 
Después, siempre en la correspondencia con Alfonso Reyes y esporádicamente con algún miembro de El Colegio de México, puede casi verse a Alonso otra vez en acción cuando desaparecen el Instituto de Filología y la $R F H^{5}$. "Desaparecer", "desmembrar" - otro de los verbos usados con frecuencia- son demasiado generales; el de 1946 fue un golpe de gracia sin derecho a confesión.

En el archivo de la $N R F H$ hay algunos recortes de periódicos en donde se anuncia la aparición inminente de la nueva revista, y de entre ellos se podrían escoger, a modo de prefacio, un par de columnas de un periódico de Buenos Aires -El Mundo, octubre, 1947- firmadas por Félix Lizaso, quien resume los avatares del Instituto de Filología desde su fundación (1923): de inspiración pidaliana, dirigido también por filólogos que procedían del Centro de Estudios Históricos de Madrid (Américo Castro, Agustín Millares Carlo, Manuel Montoliu y por último Amado Alonso en 1927). Un año después de la muerte de Pedro Henríquez Ureña (1945) "se hizo visible la condena que sobre él pesaba, cuando un acuerdo del gobierno, en septiembre de 1946, dejó fuera de sus cátedras en la Facultad de Filosofía y Letras a Amado Alonso, a la sazón invitado por la Universidad de Harvard para ofrecer cursos de literatura y lengua españolas. En justificación de la medida, se decía que el Dr. Alonso no había mostrado su amor a las instituciones docentes del país, al ausentarse aceptando la invitación”. Esto se cuenta sobre mojado, a poco más de transcurrido el año de un acto irreverente, pero comprensible: golpear sobre la cultura, para que -sabedor el resto del mundo sobre el caso de este pequeño grupo destinado al exilio- nadie levante cabeza. Pero bien visto, no fue un golpe a la cultura, sino a una de sus manifestaciones - es la paradoja-más frágil y más peligrosa, la del libro. ¡Por dios!, filosofía y letras, y, sobre esto, filología, aristocracia sin otra heráldica que los títulos de páginas acumuladas en milenios, mundo aparte, "proud of his scientific attitude" dice E. E. Cummings, y sin trincheras.

debe tener contenido valioso por muchos motivos; pero si es obra de arte, una cosa le será esencial: que nos cause placer estético". El matiz más humano de esta exposición didáctica es que Alonso pide a Reyes que le permita publicarla en el periódico La Nación, para conseguir algo de dinero.

${ }^{5} \mathrm{La}$ historia oficial se ha contado varias veces. Antonio Alatorre prologó el Índice de los tomos 1-44 con esa reseña. 
Al leer la correspondencia de 1947 se advierte que, entre todo lo que es necesario hacer, algo tiene prioridad: recuperar sin demoras la revista -o una revista- que fuera emisario, representación, símbolo de la contraintolerancia. En el cuarto día de ese año, Alonso escribe a Daniel Cosío Villegas sobre proyectos que han platicado él y Reyes: una escuela de graduados, un instituto de filología que podría comenzar en El Colegio y también, cuando Raimundo Lida pudiera venir a México, "echaríamos a andar en seguida la Revista Hispánica de Filología (ahora RHF, invirtiendo)... Harvard no está tan lejos de México. Yo dirigiría la RHF y haría viajes..." Y el 6 de marzo Alonso escribe desde Harvard: "Mi idea es dar por difunta la RFH con el doble número 1-2 de 1946, que acaba de salir (muy hermoso), y seguir ahora con otro doble número 1-2 (=3-4) de 1947”. Un par de semanas después, en un post scriptum, lamenta que Raimundo Lida no pueda llegar hasta junio, y continúa: "Empezaremos la Revista Hispánica de Filología este año. Ya tenemos artículos de Bataillon, Sánchez-Albornoz, Hatzfeld, María Rosa Lida, otro mío, otro de Spitzer, me lo dará 6 . Y promesas de Harri Meier y otros europeos. En cuanto llegue Lida se tiene que hacer una circular invitando a suscribirse a todos los que eran de la RFH, y otros se ganarían en México y Cuba. Y se debe buscar la suscripción de todas las universidades de aquí".

La enumeración de colaboradores citada arriba corresponde casi al contenido del primer ejemplar de la revista. Pero acumular materiales no era la única tarea; antes siquiera de que éstos estuvieran en condiciones de entrar a prensa, había que pensar en suscripciones, intercambios, pago de colaboraciones, lo que significaba conseguir mecenas, lo que significaba también conseguir colaboración de Columbia o Harvard. "La revista es lo más urgente y Lida puede hacerla muy bien", escribe Alonso en junio de 1947. "Estoy un poco desanimado en lo que a mi intervención toca, porque desde aquí no sé cómo conducirme con los Danieles ${ }^{7}$, ni creo que pueda influir en su fuerte voluntad. La insistencia de Lida para que extreme con

${ }^{6}$ Spitzer debe haber prometido para ese primer número un artículo sobre Cervantes, que no pudo enviar a tiempo, pero colaboró con dos notas lexicográficas -una página impresa a veces menos-, curiosidades o principios de investigación que autores diversos enviaron después para otros números de la revista.

${ }^{7}$ Daniel Rubín de la Borbolla, quien cuidaba severamente la administración, y Daniel Cosío Villegas, secretario general de El Colegio. 
ellos la exquisita cortesía me revela que no siempre lo he hecho, lo cual me llena de confusión... hablaré con Onís respecto a la concreta participación de Columbia. No sé si yo he de figurar como individuo o como miembro de Harvard, es decir si Harvard va a figurar. No sé casi nada de lo que es importante para los Danieles, y me temo no acertar. A Lida le escribo más largo y le envío los originales que tengo aquí". "No se preocupe usted por los Danieles - contesta Reyes- ni de su fuerte voluntad, mientras la mía, suave e invasora como la atmósfera ${ }^{8}$, esté todavía operante. Dígame lo que se le dé la gana y eso se hará. No se desconcierte. Ellos no saben una palabra de estas cosas y aquí estoy para hacerlo comprender así. Lida tiene empacho en comunicarse conmigo por no molestarme en mi encierro de enfermo. Pero a la hora de la decisiones será indispensable que no se dé un paso sin mi aprobación, que siempre estará sujeta a la de usted".

La respuesta de Reyes es síntesis de su amistad, de la philía, observa Gadamer en su librito sobre los inicios de la sabiduría, "que precede a todo posible valer y obrar de las instituciones de los órdenes económicos y jurídicos, las costumbres sociales..."; pero es también síntoma de una situación que, si no corría sobre rieles, funcionaba con sobreentendidos entre los comprometidos en la institución, con su administración, los Danieles como colaboradores, y Alfonso Reyes como presidente.

Aún no estaban listos los materiales de la revista, pero Alonso trabajaba en la infraestructura y, con justificada razón, aconsejaba tirar buen número de ejemplares del primero, "que con la propaganda se suele quedar luego el más cojo de la colección" ${ }^{9}$, de

${ }^{8}$ De más está encomiar el humor que con frecuencia salpica la correspondencia de Alfonso Reyes. "¿Cómo pueden ustedes, que me conocen, suponer que algo escapa a mi curiosidad y mi interés? Hoy soy, etc., como dijo Menandro mucho antes de Terencio" (septiembre, 1941); "Amado e ingrato, nos hemos cansado de buscar comunicación directa con usted... Las condiciones del Colegio de México han mudado de pronto y no «por mejoría» como en Ruiz de Alarcón" (febrero, 1942); "Abrazos a todos los abrazables. Aquí estamos pasando una tormentilla para salvar esta institución" (febrero, 1942). Y Alonso correspondía: "Con qué gusto me hace reír su carta. No tanto por lo que dice (y por lo que de nuevo me equilibra), sino por ese arte incomparable en el que usted se asume en carne y hueso en el filo de una frase" (junio, 1947).

${ }^{9}$ Como en efecto ocurre ahora; ese primer número es el más difícil de conseguir, el que desaparece de las colecciones al menor descuido. 
preocuparse por el pago a quienes colaboraban, de "ajustar los tornillos de la revista", ¿y a quién pedir dinero para los anejos? 10 "Tengo tanta ilusión en los Anejos como en la Revista. ¿Pero cómo pagarlos?” Tender líneas para las suscripciones y "presentar la nueva revista como continuación científica de la difunta, pero administrativamente desconectada del todo... Conviene que la nueva revista (NRFH? RAF?) ${ }^{11}$ tenga las características materiales y técnicas de la anterior, y que al ofrecerla a las bibliotecas se declare así".

Los redactores que Alonso sugiere a Reyes a "vuela pluma" aparecen, entre otros, en la segunda de forros del primer número, "pero como esas dos columnas son más que nada una lista de personas que aparecen aprobando y patrocinando la revista, pueden ustedes añadir. Desde luego, tiene usted que desempolvar su propio nombre de filólogo y añadirlo a la lista".

Casi todo lo que quería Alonso quedó explicado en unas cuantas líneas en la tercera de forros del primer número: "La labor del Instituto de Filología se reanuda ahora en El Colegio de México, con la ayuda de la fundación Rockefeller (División de Humanidades), del licenciado Carlos Prieto y de otros generosos amigos, y se irá dando a conocer en la Nueva Revista de Filología HispániCA, publicada con la misma orientación de la Revista de Filología Hispánica y con los mismos y nuevos colaboradores". Pero antes hubo que ajustar mucho. Falta una carta de A. Reyes a Alonso, en donde, al parecer, enumeraba una serie de condiciones, propuestas o dudas sobre el status de la revista que empedraban aún el tránsito a la nueva época. Y creo que se deben a una carta de Federico de Onís (24 de julio, 1947) a Raimundo Lida, en donde expone la situación del único número del octavo tomo de la $R F H$ en

${ }^{10} \mathrm{El}$ primer anejo de la revista (1950) fue el impresionante Juan de Mena de María Rosa Lida. Es de lamentar que en lo que tenemos de su correspondencia no queden datos de la preparación e impresión del libro. Sólo encontré tres líneas en una carta a Antonio Alatorre (22 de septiembre de 1950), comentando su traducción de Ovidio: "Acabo de leer sus Heroidas: ¡lástima tener que alinear sobre el papel todas las cosas que me gustaría decir de viva voz! Todas no serán, porque la carta saldría entonces más larga que mi Menay, apenas convaleciente Ud. de él, sería cruel perfidia infligirle una reedición”. Es una carta elogiosa a la traducción y notación de Alatorre, con exposición erudita de Ovidio, de otras traducciones, con sobreentendidos de un conocedor a otro.

${ }^{11}$ Así está escrito. Quizá Alonso pensaba todavía en la Revista Hispánica de Filología y se coló, entre sus prisas, esa A, que haría pensar en una extraña Revista Americana de Filología Hispánica. 
Buenos Aires, la deuda con los suscriptores, la bibliografía, siempre el trabajo más duro de la revista: "Antes de empezar a hacer la primera bibliografía necesito que me diga usted cuándo va a publicarse el primer número, y también la fecha en que van a salir los siguientes del año". Con todo haciéndose (entre junio yjulio de 1947 Lida envió cartas a los futuros miembros del consejo de redacción dando las explicaciones pertinentes sobre la "continuidad científica" de la nueva revista y recibió casi en seguida las respuestas positivas de los corresponsales), ¿habría sido posible detenerse a pensar en una fecha exacta para la aparición del primer número? Otro ruido era tener que pensar en algo de lo que quizá Alfonso Reyes no estaba advertido o descubrió en la carta de Onís: "Una vez que esté decidido cuándo va a salir el primer número tendremos que liquidar con la administración de Buenos Aires hasta el último número publicado (VIII, 1-2). A los suscriptores que han pagado el tomo VIII tendremos que devolverles dinero y decirles que en lo sucesivo se entiendan directamente con el Instituto de Filología de Buenos Aires, pues nosotros hemos dejado de ser con ese número representantes de la Revista de Filología Hispánica en los Estados Unidos. Creo que en esa carta, que mandaremos a todos los suscriptores, no tenemos que mencionar la nueva revista..." Sobre lo primero, era claro para Alonso y lo explica a Reyes, que la $R F H$ no salía más por "voluntad declarada del interventor del Instituto", que "no son propietarios ni de los propósitos, métodos, ni siquiera del título, que podríamos nosotros usar perpetuamente..."; y a los suscriptores "bastará con decirles «los mismos que hicieron la RFH y que ya no la van a hacer [porque el Instituto de Filología de Buenos Aires ha sido dispersado], más otros filólogos e historiadores de la literatura (Alfonso Reyes, Millares, Garcidueñas, etc.) van a publicar una [nueva ${ }^{12}$ RFH. ¿Quieren suscribirse?»"

Sin duda, la bibliografía era cuestión importante; si con los medios actuales - veloces y, en teoría, menos proclives a errorconsume tiempo razonable, en esos años la búsqueda y elaboración meticulosa de fichas no eran de tomar a la ligera. Como en lo demás, hay aquí urgencia: "Todo antes de retrasar la aparición de la NRFH”, dice Alonso. Desde el primer número de $R F H$, había relación con la Revista Hispánica Moderna del Hispanic Institute en la redacción de la bibliografía. La $R F H$ publicaba lo español, portugués, catalán, y la $R H M$ lo hispanoamericano.

${ }^{12}$ Los textos entre corchetes están tachados en la carta. 
Aunque caben dudas, en lo que Alonso da por sobreentendido, llegaría la bibliografía del Hispanic Institute, ¿y si no? ("todo antes de atrasar la aparición de la NRFH"), Alonso ofrece "una bibliografía especial de extensión conveniente: lo hecho en España desde 1936 [obra de Manuel García Blanco]. La podemos dar en el número 1 y Onís $[R H M]$ puede empezar en el número 2..." Hay que empezar la bibliografía desde cero, "Y aquí, le recomiendo que el encargado de la bibliografía se atenga a los estudios sobre distintas secciones, y que no incluya los libros (novela, biografía, etc.) traducidos al español. Que no se pase de 20 páginas por número. Hay que tener en cuenta que ahora se ha de añadir la producción europea cada día más normalizada"13. La frase ambigua de Alonso -que no se incluyeran "novela, biografía traducidos al español"-desconcierta a Manuel Durand, "encargado" de la bibliografía -segundo de Lida, aclara Reyes-, que para septiembre de 1947 ya había enviado el Hispanic Institute, estaba en prensa con todo y siglas, no pasaba de veinte páginas (trece en concreto).

Quien recuerde la antigua clasificación de la bibliografía en la $R F H$ primero y la $N R F H$ después, recordará también que era barroca y meticulosa: nada de orden alfabético, sino temas de lingüística y de literatura, de lo general a lo particular, y que los autores en las secciones correspondientes (poesía, narrativa, teatro, géneros diversos...), aparecían por generación y también de lo mayor a lo ínfimo de su obra y lo mismo los estudios críticos sobre ella. Era, más que bibliografía, casi historia del humanismo hispánico articulada hasta el detalle mínimo. Para el que la hacía era un ejercicio duro e implacablemente didáctico: reconocer ignorancias, investigar, buscar hasta el último rincón. Y luego, con aquella cantidad de fichas impresas, revisadas a conciencia - no pocas veces con la ayuda de un cajista ducho en los matices de su tipografía particular- descubrir errores que ya no se podía alterar con sonrojos. No quiero olvidar los años en que Antonio Alatorre tecleó y corrigió sin descanso las fichas de todas las revistas, homenajes y libros que llegaban a El Colegio ni los que me tocaron; en ese menester medio puede irse la vida normal y consumirse la académica.

${ }^{13}$ En la correspondencia están siempre detrás, aunque presentes, los años de guerra -la civil, la mundial-, y ahora los de postguerra: la producción, la literatura, comienza a recuperarse. 
Y para la cuestión final, Alonso remata la carta con un pedido: "le quiero hacer una declaración de deseo egoísta. Y es que la NRFH salga como dirigida por Alfonso Reyes, México, Amado Alonso, Harvard. Secretario Raimundo Lida. Esta conjunción me llenaría de orgullo y de placer, y, sobre todo, le añadiría a la NRFH consistencia y hasta haría más lógica su aparición en México. Digo lógica por más explícitamente justificada. Usted no trabajaría más de lo que, de todos modos, va a trabajar en ella. Y la revista saldría muy fortalecida. No es cortesía: No es coquetería. Es una proposición seria, después de bien pensada. Y mi deseo es que usted la acepte". Reyes le anuncia a vuelta de correo que el primer cuaderno está casi listo en pruebas, y sobre la codirección, que hablará con sus compañeros: "Agradecido. Comprendo muy bien. Pero no estoy aún convencido. Ya le escribiré más tarde sobre este extremo. Hay tiempo".

En tres cartas de A. Reyes que siguen a ésta, hay un tono de cautela, duda, presión, algo de agobio ${ }^{14}$, y no es de extrañar: empezar de cero, ganar al tiempo, Alonso lejos con sus urgencias y ansiedades, Reyes aquí, con sus obligaciones y preocupaciones, más la solicitud o fuerte sugerencia -lo anoté arriba- de que la $N R F H$ se pareciera en lo material (lo académico estaba más que resuelto) tanto como fuera posible a la $R F H$ volvía hasta la portada en cuestión algo conflictiva ${ }^{15}$. La RFH tenía un forro gris sobrio que destacaba las tintas del tí-

${ }^{14}$ El tema "dinero" entra y sale de las cartas: salario para R. Lida, para el pago de colaboraciones, falta de recursos, ¿a quién se puede pedir donativos? Los estadunidenses no son pródigos, aunque está la Fundación Rockefeller. Alfonso Reyes recurre a Carlos Prieto; de ahí que él y otros "generosos amigos" figuren en las noticias -última página del primer número. Pero eso, al parecer, era constante. En 1952, Alonso le escribe a propósito de unos cursos de verano en la Universidad Nacional Autónoma para Boyd-Bowman a pesar de que sabe "lo corto de fondos que el Colegio anda siempre". Reyes le contesta, "En cuanto al Colegio...jay, si supiera las que paso, nada me diría!". En el borrador de la carta, está tachada esta línea: "Lida nada sabe de estos problemas que nunca trascienden".

${ }^{15}$ A más de lo que se encuentra aquí y allá en la correspondencia, hay un resumen, especie de memorandum dirigido al Dr. Borbolla con fecha 25 de junio de 1947, y abajo, "Para comunicar al Sr. Lida", en cuyos puntos cuatro y cinco dice: "hay que presentar la nueva revista como continuación científica de la difunta, pero enteramente desvinculada de ella en lo jurídico y administrativo". "Que la nueva revista mantenga las características materiales y técnicas de la anterior, y que así se declare al ofrecerla a las bibliotecas". 
tulo y de una pequeña viñeta ubicada en el centro. En carta donde enumera puntos que esperan solución (6 de octubre, 1947), Reyes comenta, "por ser menos comprometedor, resolvimos no poner dibujo en la portada". ¿Comprometedor en qué sentido? Más cautela. En todo caso, a partir del primer tomo figuró al pie del forro de la $N R F H$ el maguey que conserva, y el Hispanic Institute apareció sólo en la bibliografía.

En el tomo tercero, 1949, se advierte en las noticias "Desde el presente número, la Nueva Revista de Filología Hispánica está patrocinada por El Colegio de México y por la Universidad de Harvard, la cual, deseosa de fomentar los estudios hispánicos ha establecido un fondo especial... generosamente iniciado por Mr. George L. Lincoln ex profesor del departamento de lenguas romances de esa universidad". Pero llegado el momento, después del homenaje a Amado Alonso, cuando Alfonso Reyes se hizo cargo de la dirección, también desapareció. En una carta, que firma como presidente de la Junta de Gobierno (17 de junio, 1952), que he leído más de una vez porque en cada línea muestra eso que definió como sus "escamas diplomáticas", Reyes desprendió a la revista de Harvard: "Siempre será para nosotros -dice en el segundo párrafo- un orgullo el que nuestras dos instituciones se hayan asociado, siquiera nominalmente, y muy especialmente ello ha sido grato para mí, por lo mismo que la Universidad de Harvard me cuenta entre los suyos desde 1942, en condición de Doctor en Letras Honoris Causa. La Junta de Gobierno del Colegio de México se atreve sólo a presentar esta cuestión ante usted por considerarse obligada a desligar a la Universidad de Harvard de su anterior y benévolo compromiso".

Pero, y vuelvo al 6 de octubre de 1947, Reyes no aceptó la codirección: "Se resuelve que la lleve usted solo, sin añadir mi nombre, pues ello desvirtuaría mi propósito. Lo cual no significa para nada que yo me desatienda de ella. Aquí estoy para tirar el carro con usted, como dos buenos hermanos que siempre somos. Ya no lo discuta por favor. Está resuelto".

En octubre de ese año, Reyes comunica que Spitzer no enviará su prometido artículo cervantino, que quizá Américo Castro mande algo ${ }^{16}$ y que "el número primero está ya para caer del árbol”. En enero y febrero de 1948, la prensa cultural mexi-

${ }^{16}$ Aunque ya en una carta de julio de ese año, era vaga la promesa de Castro de enviar algo sobre el Guzmán o sobre Boccaccio y Lope de Vega. 
cana saludó la aparición de la NRFH (o NRdeFH, como figura en algunos). El columnista de Últimas Noticias (Julián Amo) describe en pormenor el contenido de ese primer número y cierra la nota deseando a la publicación "la larga vida que su calidad merece". Es un ejemplar pulcro, con mucho aire en sus márgenes amplios, no sólo hecho con profesionalismo. Lo que conmueve cuando se recorre ese primer cuaderno es advertir que está apuntalado por algo que me gustaría describir como fidelidad de la cofradía del hispanismo. Desde Buenos Aires el antiguo fan del Instituto de Filología (Félix Lizaso), resume la situación de la nueva revista que imagina en noviembre de 1947: “...así como los hombres que dieron vida y espíritu a esa publicación $[R F H]$ han encontrado acogedores refugios para sus vidas y sus empeños, de igual modo la revista ha hallado el amparo de otro pueblo hermano donde tendrá nueva y feliz vida. En México reaparecerá próximamente. Alfonso Reyes nos comunica la buena acogida que allí se le ha dispensado para que esa «criatura migratoria» siga en su vuelo activo y creador... ¿No es consolador que así se salve ese caudal de fuerzas culturales que la incomprensión dispersó?”

A pesar de que en 1948 Alonso pedirá cambio de tipografía porque la actual no es la indicada (no son claras las cursivas, faltan matrices especiales, etc.) y hará brotar el mal humor de Cosío Villegas, la aparición del primer número le devolvió el ánimo que, sin previo aviso, le arrebató no sólo la incomprensión, como dice Lizaso, también la más mezquina manifestación de la condición humana. En febrero de 1948, escribe a Reyes, "Yo, contentísimo. La RFH [sic, y se entiende] seguirá viviendo hasta hacerse vieja, y a su calor puede y debe salir una decente nidada de filólogos mexicanos". No fue del todo así -no hubo nidada de filólogos-, pero ésta, la primera revista de El Colegio, ha vivido hasta alcanzar madurez, poniendo a distancia, siempre que fue posible, el oportunismo individual y el de las corrientes efímeras de las disciplinas que la nutren.

Cuando Alonso decidió dar por terminada la $R F H$, corría el riesgo de acabar con todo; tenía en sus manos algo muy frágil, porque era inevitable terminar con una revista cuando el perfil de la siguiente no se dibujara aún con nitidez. Pero no correr ese riesgo habría significado dar razón a los que terminaron con su revista y el Instituto. Golpear, pues, no con el mismo hierro, pero no con menos fuerza. Hubo, qué dudar, coincidencias favorecedoras: la amistad larga con Alfonso Reyes, más la institución que se 
abría paso con un estilo nada común. En 1951, invitado a colaborar en el cuarto centenario de la Universidad Nacional Mayor de San Marcos de Lima, Reyes envió un breve artículo en el que describe El Colegio y sus actividades: "Siempre que hace falta, el Colegio se asocia gustosamente a cualquiera institución para llevar a buen término cualquier programa de cultura... A objeto de evitar intolerables recomendaciones venidas de campos extraños, y de desalentar ambiciones de mero incentivo vanidoso, el Colegio no acostumbra publicar folletos de propaganda, trabaja en silencio, en cenobio. Se evitan las solemnidades ociosas, pues el estado de civilización no requiere nunca un ceremonial excesivo. El buen entendimiento preside las labores de esta modestísima casa".

Martha Elena Venier El Colegio de México 